|| ISSN(online): 2589-8698 || ISSN(print): 2589-868X || International Journal of Medical and Biomedical Studies

Available Online at www.ijmbs.info

PubMed (National Library of Medicine ID: 101738825)

Index Copernicus Value 2018: 75.71

Original Research Article

Volume 3, Issue 6; June: 2019; Page No. 22-27

\title{
A STUDY OF NEONATES WITH BIRTH ASPHYXIA FOR SEQUELAE OVER 2 YEARS
}

\author{
Dr. Y.Vamseedhar ${ }^{1}$, Dr. B.K.Niranjan ${ }^{2}$ \\ ${ }^{1}$ Associate Professor, ${ }^{2}$ Assistant Professor, \\ Department of Pediatrics, Government Medical College, Govt. General Hospital, Kadapa, AP.
}

Article Info: Received 15 April 2019; Accepted 04 June. 2019

DOI: https://doi.org/10.32553/ijmbs.v3i6.285

Corresponding Author: Dr.B.K.Niranjan, Assistant Professor, Department of Pediatrics, Government Medical College, Kadapa, A.P

Conflict of interest: No conflict of interest.

\begin{abstract}
Introduction: Birth asphyxia is associated with reduction in the arterial oxygen tension, accumulation of carbon dioxide and fall in blood $\mathrm{pH}$. Acidosis occurs due to anerobic utilization of glucose, production of lactic acid and accumulation of carbon dioxide.

Aim: To study outcome of neonates who suffered birth asphyxia and Hypoxic-ischemic encephalopathy (HIE) in a teaching hospital over a period of 2 years.

Materials \& Methods: 325 neonates with birth asphyxia and hypoxic ischemic encephalopathy were studied, with well defined inclusion and exclusion criteria. They were treated according to standard protocols. Observations : 106 neonates of HIE-I, 58 neonates of HIE-II, and 59 neonates of HIE-III were followed up: for various outcomes like death due to complications, cerebral palsy, developmental delay with epilepsy, hearing handicap etc.
\end{abstract}

Results: In HIE-I no case progressed to cerebral palsy, in HIE-II 24.13\% progressed into CP and in HIE-III 54.2\% developed spastic cerebral palsy.

Conclusion: Infants with severe grades of HIE have increased risk of long term neurological sequlae.

Keywords: Neonate, Birth asphyxia, Acidosis, Neonatal encephalopathy

\section{Introduction:}

The World Health Organization (WHO) estimates that globally, between four and nine million newborns suffer birth asphyxia each year leading to an estimated 1.2 million deaths and about the same number of infants who develop severe disability. WHO estimates for global neonatal deaths caused by birth asphyxia are $29 \% .{ }^{1,2}$

Birth asphyxia is associated with reduction in the arterial oxygen tension, accumulation of carbon dioxide and fall in blood $\mathrm{pH}$. Acidosis occurs due to anaerobic utilization of glucose, production of lactic acid and accumulation of carbon dioxide. These biochemical changes cause constriction of relatively muscular pulmonary arterioles and raise the pulmonary arterial pressure. This results in reduced filling of the left heart and right-to-left shunts.

The American Academy of Pediatrics has proposed that the diagnostic label of perinatal asphyxia should be reserved to describe an infant who manifests all of the following features : ${ }^{3}$

$>$ Core umbilical artery $\mathrm{pH}$ of $<7.0$ with a base deficit of $>10 \mathrm{mEq} / \mathrm{L}$.

$>$ Neonatal neurologic manifestations suggestive of hypoxic-ischemic encephalopathy (HIE).

$>$ Evidences of multisystem organ dysfunction (e.g. cardiovascular, renal, gastrointestinal, hematologic or pulmonary). 
Neonatal encephalopathy, following severe birth asphyxia or perinatal hypoxia is referred to as hypoxic ischemic encephalopathy (HIE). ${ }^{4}$ Cerebral ischemia occurs as a consequence of cerebral edema (which compresses cerebral vessels) and reduced cerebral perfusion due to myocardial dysfunction as a result of hypoxic cardiomyopathy. Following severe birth asphyxia, $25 \%$ infants are likely to develop the syndrome of HIE.

In acute total asphyxia, which is rare in human clinical setting, there is no time for the compensatory mechanisms to sustain cerebral circulation leading to severe damage to the basal ganglia, thalamus and brainstem. It usually leads to death. In the more common variety of partial asphyxia in the human infant, the homeostatic mechanisms divert the blood from less vital organs to the brain, heart and adrenals.

Hypoxic damage to neurons may lead to both cytotoxic and vasogenic cerebral edema though brain swelling per se is not prominent feature of HIE in the human newborn. Severe hypoxia causes selective neuronal necrosis in hippocampus, thalamus, basal ganglia, brainstem and cerebellum. "Water shed infarcts" due to preferential blood flow to brainstem rather than cerebrum, leads to parasagittal cerebral injury in term and post-term infants. In preterm babies, asphyxial damage on the other hand leads to peri ventricular leukomalacia.

\section{Objectives:}

To study outcome of neonates who suffered birth asphyxia and Hypoxic ischemic encephalopathy in a teaching hospital (Government General Hospital, Kadapa) at the end of 2 years.

\section{MATERIALS AND METHODS}

The study was done in a tertiary care teaching hospital over a period of 2 years. Only inborn babies were selected into the study. Only term babies are considered and all premature, IUGR, LBW babies are excluded from the study. The study period is from November 2016 to April 2019. Total number of deliveries done in Govt. General Hospital, Kadapa in the above said period are 2842. Among them total number of normal neonates was 2451 .

The clinical syndrome of Hypoxic ischemic encephalopathy (HIE) was considered when APGAR Score of 3 or less at $5 \mathrm{~min}$. or later.

All neonates with congenital malformations and surgical problems were excluded from the study. Total number of babies who were affected from birth asphyxia and developed HIE were 325.

When classified according to Sarnat \& Sarnat and Levene grading among to the total 325 babies; 148 neonates were categorized into HIE Stage I (HIE-I) 96 neonates were categorized into HIE Stage II (HIE-II) and 81 neonates were categorized into HIE Stage III (HIE-III) with in first $24 \mathrm{hr}$. of life.

Table 1: Sarnat ${ }^{5}$ and Sarnat staging of Hypoxic ischemic encephalopathy

\begin{tabular}{|l|l|l|l|}
\hline Features & Stage I & Stage II & Stage III \\
\hline Consciousness & Hyperalart & Lethargic & Comatose \\
\hline Muscle tone & Normal & Hypotonic & Flaccid \\
\hline Tendon reflexes & Brisk & Exaggerated & Absent \\
\hline Myoclonus & Present & Present & Absent \\
\hline Sucking & Normal & Weak & Absent \\
\hline Moros response & Exaggerated & Incomplete & Absent \\
\hline $\begin{array}{l}\text { Oculocephalic reflex } \\
\text { (Doll's eyes) }\end{array}$ & Normal & Over reactive & Reduced or absent \\
\hline Pupils & Dilated and reactive & Constricted & $\begin{array}{l}\text { Dilated and fixed, } \\
\text { unequal in size }\end{array}$ \\
\hline Respiration & Regular & Periodic & Apneic attacks \\
\hline Heart rate & Normal & Bradycardia & Variable \\
\hline Seizures & Absent & Common & Uncommon \\
\hline EEG & Normal & $\begin{array}{l}\text { Low voltage periodic/ or } \\
\text { paroxysmal }\end{array}$ & Periodic, isoelectric \\
\hline
\end{tabular}


Table 2: Levene ${ }^{6}$ grading of hypoxic-ischemic encephalopathy

\begin{tabular}{|l|l|l|l|}
\hline Features & Mild & Moderate & Severe \\
\hline Consciousness & Irritable & Lethargic & Comatose \\
\hline Tone & Some hypotonia & Moderate hypotonia & Severe hypotonia \\
\hline Seizures & Nil & Present & Persistent \\
\hline Sucking / breathing & Poor suck & Unable to suck & $\begin{array}{l}\text { Unable to sustain } \\
\text { spontaneous breathing }\end{array}$ \\
\hline
\end{tabular}

Seizures occured approximately in 50\% of affected infants mostly within 6 to 12 hours after birth and invariably by 36 hours of age. Term babies produced gross seizures. There is CNS irritability, jitteriness, excessive crying followed by lethargy, inactivity, apnea spells and stupor. Anterior fontanel may be level or bulging due to cerebral edema and IVH.

Efforts were made to prevent further hypoxic damage to the brain and correct any associated acidbase and metabolic abnormalities. If despite active resuscitation efforts, 5-minute APGAR score is less than 5, the infant was admitted in the neonatal intensive care unit for close monitoring and management.

Vital signs were monitored preferably with the help of multi-channel vital sign motor. Detailed record was maintained to assess CNS integrity with the help of Sarnat staging system.

Periventricular and intraventricular hemorrhage was best diagnosed with the help of ultrasound examination but was clinicaly suspected by features of sudden pallor/jaundice, fall in hematocrit, subtle seizures, bulging anterior fontanel and marked hypotonia. Serum electrolytes were monitored. Sepsis screening and blood culture was taken to make early diagnosis of bacterial infection.

Ultrasound of the brain was done during 4 to 7 days of life for the diagnosis of periventricularintraventricular hemorrhage and leukomalacia. Hypoechoic areas due to cerebral infarction were seen in severely asphyxiated term babies.

CT scan was more useful to diagnose para sagittal infarction and ischemic changes and it was done after the age of 2 weeks.

The baby was nursed in a thermo neutral environment with head raised by $30^{\circ}$ to prevent further elevation of intracranial pressure. The infant was intubated and attached to mechanical ventilator and provided with hyperventilation to maintain $\mathrm{PaO}_{2}$ between 80 and $100 \mathrm{~mm} \mathrm{Hg}$ in term babies, when required. Oxygen saturation on pulse oximeter was maintained between 90 and 95\%.

During first 48 hours, $10 \%$ dextrose solution (twothirds of maintenance requirements) without sodium and potassium was infused. Acidosis, hypoglycemia, hyperkalemia and hypocalcemia (QoTc $>0.2 \mathrm{sec}$ ) were identified and appropriately managed. Blood glucose was maintained between 60 and $100 \mathrm{mg} / \mathrm{dL}$. Calcium gluconate $(150-200 \mathrm{mg} / \mathrm{kg} /$ day $)$ was administered intravenously for initial 48 hours to counteract hypocalcemia due to intracellular flux of calcium, elevated serum potassium and phosphate levels.

Hypotension and poor tissue perfusion was identified and promptly managed by administration of normal saline or Ringer's lactate and by use of dopamine 5$10 \mathrm{mcg} / \mathrm{kg} / \mathrm{min}$ when myocardial dysfunction was strongly suspected. Furosemide in a dose of 1.0 $\mathrm{mg} / \mathrm{kg}$ every 12 hours intravenously for 4 doses was given especially when there was oliguria to ensure diuresis and reduce intracranial pressure. A loading dose of phenobarbitone $20 \mathrm{mg} / \mathrm{kg}$ followed by $5 \mathrm{mg} / \mathrm{kg} / \mathrm{d}$ as maintenance dose intravenously was given. When seizures are unresponsive to a loading dose of phenobarbitone, a loading dose phenytoin 20 $\mathrm{mg} / \mathrm{kg}$ follwed by maintenance dose of $5-7 \mathrm{mg} / \mathrm{kg} / \mathrm{d}$ intravenously was given.

In majority of neonates with HIE seizure activity disappeared within 3 to 10 days, at the time of discharge, all anticonvulsants except phenobarbitone were stopped. The infant were re-evaluated at the age of 3 months. If there was no recurrence of seizures and both CNS status and EEG examination are normal, phenobarbitone was stopped. When phenobarbitone is continued beyond 3 months, the infant was re-evaluated at the age of six months to decide whether phenobarbitone therapy would be continued as in case of epilepsy or terminated at this stage.

RESULTS: 
The above neonates are followed up during hospital stay and after discharge also.

Table 1: Month wise details

\begin{tabular}{|l|l|l|l|}
\hline Month & HIE-I & HIE-II & HIE-III \\
\hline Nov. 16 & $30(7)$ & $18(6)$ & $16(4)$ \\
\hline Dec. 16 & $22(3)$ & $17(8)$ & $11(3)$ \\
\hline Jan. 17 & $23(8)$ & $16(4)$ & $10(2)$ \\
\hline Feb. 17 & $21(10)$ & $19(4)$ & $13(5)$ \\
\hline Mar. 17 & $28(9)$ & $14(7)$ & $17(6)$ \\
\hline Apr. 17 & $24(5)$ & $12(9)$ & $14(2)$ \\
\hline
\end{tabular}

The figures in brackets represent neonates who were lost to follow up. (did not come for follow up). Those infants who are discharged successfully were followed up until their 2nd birthday.

Table 2: Month wise details of followed up infants

\begin{tabular}{|l|l|l|l|}
\hline Month & HIE-I & HIE-II & HIE-III \\
\hline Nov. 16 & 23 & 12 & 12 \\
\hline Dec. 16 & 19 & 9 & 8 \\
\hline Jan. 17 & 15 & 12 & 8 \\
\hline Feb. 17 & 11 & 15 & 8 \\
\hline Mar. 17 & 19 & 7 & 11 \\
\hline Apr. 17 & 19 & 3 & 12 \\
\hline Total & $\mathbf{1 0 6}$ & $\mathbf{5 8}$ & $\mathbf{5 9}$ \\
\hline
\end{tabular}

All the above infants were followed up during hospital stay and after discharge until 2 years and the observations are tabulated below.

Table 3: HIE - I

\begin{tabular}{|l|l|l|l|l|l|}
\hline Month of Birth & No. of Neonates & Death & Dev. Delay & Cerebral Palsy & Normal \\
\hline Nov. 16 & 23 & 2 & 2 & 0 & 19 \\
\hline Dec. 16 & 19 & 1 & 3 & 0 & 15 \\
\hline Jan. 17 & 15 & 1 & 1 & 0 & 13 \\
\hline Feb. 17 & 11 & 0 & 0 & 0 & 11 \\
\hline Mar. 17 & 19 & 1 & 4 & 0 & 14 \\
\hline Apr. 17 & 19 & 1 & 2 & 0 & 16 \\
\hline Total & $\mathbf{1 0 6}$ & $\mathbf{6}$ & $\mathbf{1 2}$ & $\mathbf{0}$ & $\mathbf{8 8}$ \\
\hline
\end{tabular}

Among the total 106 neonates who were diagnosed as HIE-I within 1st 24 hours of life 6 neonates died during hospital stay. The cause of death for 4 neonates was meconium aspiration syndrome with respiratory failure and 2 deaths were due to congenital pneumonia. Mild to moderate developmental delay was noted in 12 infants at the end of 2 years. 88 infants were completely normal at the end of 2 years follow up. No infants suffered cerebral palsy.

Table 4: HIE - II

\begin{tabular}{|l|l|l|l|l|l|}
\hline Month of Birth & No. of Neonates & Death & Epilepsy & Cerebral Palsy & Normal \\
\hline Nov. 16 & 12 & 2 & 4 & 4 & 2 \\
\hline Dec. 16 & 9 & 1 & 1 & 2 & 5 \\
\hline Jan. 17 & 12 & 2 & 3 & 3 & 4 \\
\hline Feb. 17 & 15 & 4 & 2 & 4 & 5 \\
\hline Mar. 17 & 7 & 1 & 1 & 1 & 4 \\
\hline Apr. 17 & 3 & 0 & 1 & 0 & 2 \\
\hline
\end{tabular}




\begin{tabular}{|l|l|l|l|l|l|}
\hline Total & 58 & 10 & 12 & 14 & 22 \\
\hline
\end{tabular}

Among 58 Neonates who suffered HIE - II 10 neonates died during hospital stay ( 5 due to MAS with respiratory failure, 4 due to pneumonia with sepsis and 1 due to acute renal failure with sepsis). 10 infants were kept on oral phenobarbitone at discharge and stopped phenobarbitone at the end of 6 months but were completely normal (not epileptic) at the end of 2 years. 12 neonates did not require phenobarbitone at discharge and were normal to follow up at the end of 2 years. 12 neonates developed cerebral palsy (Spastic quadriplegia) at the end of 2 years. 12 neonates developed mild to moderate developmental delay with epilepsy requiring long term anticonvulsants at the end of 2 years.

Table 5: HIE - III

\begin{tabular}{|l|l|l|l|l|l|}
\hline Month of Birth & No. of Neonates & Death & Epilepsy with dev. delay & Cerebral Palsy & Normal \\
\hline Nov. 16 & 12 & 3 & 2 & 7 & 0 \\
\hline Dec. 16 & 8 & 2 & 1 & 5 & 0 \\
\hline Jan. 17 & 8 & 1 & 1 & 6 & 0 \\
\hline Feb. 17 & 8 & 4 & 0 & 4 & 0 \\
\hline Mar. 17 & 11 & 5 & 2 & 4 & 0 \\
\hline Apr. 17 & 12 & 3 & 3 & 6 & 0 \\
\hline Total & $\mathbf{5 9}$ & $\mathbf{1 8}$ & $\mathbf{9}$ & $\mathbf{3 2}$ & $\mathbf{0}$ \\
\hline
\end{tabular}

Among the 59 neonates who suffered HIE-III 18 died during hospital stay cause of death being MAS with respiratory failure in 11 neonates, Pneumonia with Sepsis in 4 neonates and Acute renal failure with Sepsis in 3 neonates. 9 Neonates developed moderate developmental delay with epilepsy requiring long term multiple anticonvulsants. 32 neonates finally developed Spastic Cerebral Palsy with Quadriplegia at the end of 2 years follow up. In the 9 neonates who developed moderate developmental delay with epilepsy sensorineural hearing loss was also detected which was confirmed by BERA (Brain Stem Evoked Response Audiometry).

\section{DISCUSSION}

In the study group among the 106 neonates with HIEI $83 \%$ (i.e. 88 ) were completely normal neurologically at the end of 2 years on follow up. $11.3 \%$ (i.e.12) had mild to moderate developmental delay. Death occurred in $5.6 \%$ (i.e. 6 ) due to complications with $0 \%$ (Zero) cases progressing to cerebral palsy. Among 58 neonates with HIE - II $37.9 \%$ (22) were completely normal at the end of 2 years follow up. $24.13 \%$ (14) developed cerebral palsy.

20.68\% (12) developed epilepsy with moderate developmental delay at the end of 2 years. 9.4\% (10) died due to complications before getting discharged. Among 59 neonates with HIE-III no neonate was normal at the end of 2 years follow up. 54.2\% (32) developed Spastic Cerebral Palsy with Quadriplegia. $15.25 \%$ (9) developed epilepsy with moderate developmental delay at the end of 2 years $30.5 \%$ (18) died during hospital stay due to various complications before being discharged.

When the above observations were subjected to statistical analysis our results $(P<0.01)$ confirm that infants with Severe HIE had increased risk of long term neurological sequelae and it is a good predictor of subsequent handicap. The commonest neuro motor sequelae following birth asphyxia was cerebral palsy of varying grades and severity.

Development of seizures and other clinical evidences of HIE were associated with increased risk of CP. ${ }^{7-12}$ Persistence of abnormal neurological behaviour, poor tone, pupillary changes incomplete or absent moro reflex etc. for more than one week was associated with poor long term outcome. ${ }^{13-20}$ During follow-up, detailed neurological and developmental examination was conducted to identify early clinical markers of CP.

Early clinical markers of cerebral palsy that were observed are

- Episodes of inconsolable crying, chewing movements, excessive sensitivity to light or sound, etc.

- Persistent asymmetric neck tonic posture beyond 4 weeks.

- Clenched fists (cortical thumb) beyond 8 weeks.

- $\quad$ Lack of social smile by 6 weeks. 
- Abnormalities in tone (hypertonia in lower limbs and hypotonia in neck/upper limbs).

- Paucity or absence of playful or fidgety limb movements during 6-12 weeks.

- Persistence of automatic reflexes beyond 4-5 months.

- Slow head growth.

\section{CONCLUSION:}

If following resuscitation of an asphyxiated neonate there are no neurological abnormalities during early neonatal period it indicates normal neuromotor development on follow up. Infants with severe grades of HIE (II and III) will have increased risk of long term neurological sequelae like cerebral palsy and epilepsy and it is a good predictor of subsequent handicap.

\section{ACKNOWLEDGEMENTS}

We would like to thank all the study participants and the authors from where we have cited the references for publication of this article.

\section{REFERENCES}

1. ACOG Committee Opinion. Number 326, December 2005. Inappropriate use of the terms fetal distress and birth asphyxia. Committee on Obstetric Practice, American College of Obstetricians and Gynecologists. Obstet Gynecol. 2005 Dec; 106(6):1469-70.

2. Hamilton BE, Martin JA, Ventura SJ. Births: preliminary data for 2012. Natl Vital Stat Rep. 2013 Sep; 62(3):1-20.

3. American College of Obstetrics and Gynecology., Task Force on Neonatal Encephalopathy and Cerebral Palsy., American Academy of Pediatrics. Neonatal Encephalopathy and Cerebral Palsy: Defining the Pathogenesis and Pathophysiology. Edited by Washington, DC, American College of Obstetricians and Gynecologists, 2003.

4. Long $\mathrm{M}$, Brandon $\mathrm{DH}$. Induced hypothermia for neonates with hypoxic-ischemic encephalopathy. J Obstet Gynecol Neonatal Nurs. 2007 May-Jun; 36(3):293-8.

5. Sarnat HB, Sarnat MS. Neonatal encephalopathy following fetal distress. Arch Neurol 1975, 33:696.

6. Levene MI. The asphyxiated newborn infant. In Levene MI, Lilford RJ, ed. Fetal and neonatal neurology and neuro-surgery. Edinburgh; Churchil Livingstone, 1995: 405-426.

7. Ali Z, Khadije D, Elahe A, et al. Prophylaxis of ophthalmia neonatorum: comparison of betadine, erythromycin and no prophylaxis. J Trop Pediatr 2007, 53 (6):388-392.

8. American Academy of pediatrics, American Heart Association. Textbook of Neonatal Resuscitation. 6th ed. Dallas (TX): Elk Grove Village (IL), 2011.

9. American Academy of Pediatrics and American College of Obstetricians and Gynecologists. In: Guidelines for perinatal Care. Gilstrap LC, Oh W (Eds.) 6th Ed. Elk Grove Village III. American Academy of Pediatrics 2010. 187.

10. Bhatia BD. New NRP guidelines 2010. J Neonatol 2011, 25: 9-16.

11. Deorari AK, Paul VK, Singh M.Birth asphyxia and neuro developmental outcome. Indian Pediatr 1989, 26:293.

12. Gupta JM, Tizard JPM. The sequence of events in neonatal apnea. Lancet 1967, II:55.

13. International Guidelines for Neonatal Resuscitation: An Excerpt from the Guidelines 2000 for Cardiopulmonary Resuscitation and Emergency Cardiovascular Care; International Consensus on Science. Pediatrics 2000, 106: 116.

14. Nelson KB, Ellenberg JH. Antecedents of cerebral palsy : Multivariate analysis of risk. $N$ EngJ Med 1986, 315: 81-86.

15. Neonatal resuscitation: India. National neonatology Forum of India, 2nd edition, 2014.

16. Paul VK, Shankar V, Deorari AK, Singh $M$. Tracheal suction in meconium-stained neonates. J Pediatr 1989, 144:508.

17. Paul VK, Singh $M$, Sundaram KR, Deorari AK. Correlates of mortality among hospital-born neonates with birth asphyxia in Delhi, Nat Med J India 1997, 10:54-57.

18. Raju TNK, Doshi U, Vidyasagar D. Low cerebral perfusion pressure: An indicator of poor prognosis in asphyxiated term infants, Brain Dev 1983, 5:478.

19. Shankaran S. Current status of hypothermia for hypoxemic ischemia of the new born. Indian J Pediatr 2014, 81(6):578-584.

20. Singh M. Diagnosis and management of perinatal asphyxia: current concepts. Indian Pediatr 1994, 31:1169-1174. 